\title{
Un plan de cuentas social y ambiental no financiero y los principios del Pacto Global de Naciones Unidas*
}

[Artículos]

\author{
Norma B. Geba** \\ Marcela C. Bifaretti ${ }^{* * *}$ \\ Andrea V. Pascuzzi Rey****
}

Recibido: 13 de octubre de 2020

Aprobado: 11 de enero de 2021

Citar como:

Geba, N., Bifaretti, M. y Pascuzzi, A., (2021). Un plan de cuentas social y ambiental no financiero y los principios del Pacto Global de Naciones Unidas. Revista Activos, 19(1).

https://doi.org/10.15332/25005278.6682

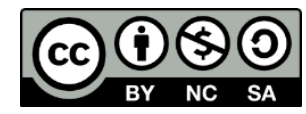

\footnotetext{
* Este artículo se desarrolla en el marco del Proyecto I+D "Contabilidad social y ambiental: su inclusión como contenido curricular básico y obligatorio de la carrera de contador público en universidades argentinas", acreditado ante la Universidad Nacional de La Plata, República Argentina.

** Doctora en Ciencias de la Administración, Universidad Nacional de La Plata (UNLP) (título en trámite). Docente investigadora UNLP, Facultad de Ciencias Económicas. Correo electrónico: normageba@econo.unlp.edu.ar; ORCID: https://orcid.org/0000-0001-7017-8603 *** Magíster en Administración de Empresas, Universidad Nacional de La Plata (UNLP). Docente investigadora UNLP, Facultad de Ciencias Económicas. Correo electrónico:

marcela.bifaretti@econo.unlp.edu.ar; ORCID: https://orcid.org/0000-0002-4187-9205

**** Contador público, Universidad Nacional de La Plata (UNLP). Adscripta graduada e investigadora en formación UNLP, Facultad de Ciencias Económicas. Correo electrónico: andrea.pascuzzi@econo.unlp.edu.ar;ORCID: https://orcid.org/0000-0002-0377-885X
}

\section{Revista Activos}

ISSN: 0124-5805 | e-ISSN: 2500-5278 | DOI: https://doi.org/10.15332/25005278

Vol. 19 N.o 1 | enero-junio de 2021 


\section{Resumen}

Iniciativas internacionales de reconocida importancia han realizado propuestas para la elaboración y emisión, por parte de las organizaciones económicas, de informes sobre aspectos económicos, financieros, sociales y ambientales para un desarrollo más sostenible y el Pacto Global trasciende diversas iniciativas. Se rescatan investigaciones y desarrollos sobre una considerada especialidad contable social y ambiental con enfoque socioambiental, complementario del económicofinanciero. En este artículo, el objetivo específico es completar un plan de cuentas contable con enfoque socioambiental no financiero para los Objetivos de Desarrollo Sostenible, considerando los Principios del Pacto Global de Naciones Unidas. Se realizan análisis inductivos y deductivos, se compara lo constituido con lo constituyente, triangulando con las memorias de sostenibilidad, y se completa un plan de cuentas con aspectos del Pacto Global. Se infiere que es posible completar un plan de cuentas, básico y flexible, con enfoque socioambiental no financiero para los Objetivos de Desarrollo Sostenible, a partir de los Principios del Pacto Global de Naciones Unidas.

Palabras clave: sostenibilidad, contabilidad social y ambiental, proceso contable, plan de cuentas, Pacto Global de Naciones Unidas.

Clasificación JEL: M49, Q56.

\section{A non-financial social and environmental chart of accounts and the principles of the United Nations Global Compact}

\section{Abstract}

International initiatives of recognized importance have made proposals for the preparation and issuance, by economic organizations, of reports on economic, financial, social and environmental aspects for a more sustainable development and the UN Global Compact transcends various initiatives. Research and developments on a considered social and 
environmental accounting specialty with a socio-environmental approach, complementary to the economic-financial one are rescued. In this article, the specific objective is to complete a chart of accounts with a non-financial socio-environmental approach for the Sustainable Development Goals, considering the Principles of the United Nations Global Compact. Inductive and deductive analyses are carried out, comparing the constituted with the constituent, triangulating with sustainability reports, and completing a chart of accounts with aspects of the Global Compact. It is inferred that it is possible to complete a basic and flexible chart of accounts, with a non-financial socio-environmental approach for the Sustainable Development Goals, based on the Principles of the United Nations Global Compact.

Keywords: sustainability, social and environmental accounting, accounting process, chart of accounts; United Nations Global Compact.

JEL classification: M49, Q56.

\section{Introducción}

Diversos lineamientos internacionales de reconocida importancia han realizado propuestas para la elaboración y emisión, por parte de las organizaciones económicas, de informes de aspectos económicos, financieros, sociales y ambientales desde distintos ángulos. De dichas propuestas se observa en la actualidad la existencia de algunas alianzas. La necesidad de información social y ambiental es considerada desde hace más de veinte años. En 1999 se propone en el Foro de Davos la idea de un Pacto Global entre las Naciones por medio de la promoción de un conjunto de valores universales entendidos fundamentales para satisfacer las necesidades de la población global. El mencionado Pacto Global puede ser entendido como un punto de inflexión, trasciende diversas iniciativas y sus principios se vinculan con los Objetivos de Desarrollo Sostenible (ODS). 
En el año 2020, desde la Federación Internacional de Contadores (IFAC) (2020), puede interpretarse que la profesión contable tiene un papel clave para la toma de decisiones que se basan en la evidencia, en recopilar información confiable y en presentar informes corporativos consistentes y comparables. La participación activa de la profesión en este tema puede maximizar beneficios de una solución global para emitir informes no financieros que sirvan a los accionistas y al interés público en general. El documento de seguimiento de Accountancy Europe (2020) da continuación a otro para establecer estándares interconectados que aborden temas de información financiera y "no financiera (NFI) como el cambio climático, la degradación ambiental, los derechos humanos y las preocupaciones sociales" (p. 1). Entre las conclusiones clave de los comentarios recibidos se afirma: "El objetivo final debería ser una solución de sistema para ofrecer estándares globales de informes NFI conectados a la información financiera”. (p. 2)

En el marco de sucesivos proyectos de investigación y desarrollo acreditados ante la Universidad Nacional de La Plata, se han realizado investigaciones sistemáticas y desarrollos sobre la considerada especialidad contable social y ambiental, con enfoque socioambiental y complementaria a la línea económico-financiera tradicional. Como resultado de ello, se ha inferido que el enfoque contable económicofinanciero tradicional responde a un estudio de parte de la realidad de las organizaciones económicas que, si bien es muy importante, es insuficiente para potenciar el cumplimiento de los ODS.

$\mathrm{Al}$ entender que para la correcta aplicación práctica de los marcos conceptuales doctrinarios y normativos contables es conveniente un adecuado proceso contable, se ha abordado y adaptado el tradicional proceso contable del enfoque económico-financiero hacia el socioambiental. Para ello, se ha considerado una perspectiva amplia del 
proceso contable que permite analizar de manera integrada, al menos, tres o cuatro subprocesos interrelacionados: 1) subproceso de descripción y explicación cualitativa y cuantitativa; 2) subproceso de control; 3) subproceso comunicacional; y 4) subproceso de auditoría, aseguramiento y similares. Dentro del subproceso de descripción y explicación cualitativa y cuantitativa, se han trabajado cuatro etapas relacionadas: captación, clasificación, medición y registro.

Para la etapa de captación, se ha observado documentación respaldatoria útil para el enfoque socioambiental en el proceso contable tradicional, así como la posibilidad de su adecuación y ampliación para la información que se requiera en las memorias de sostenibilidad de la Global Reporting Initiative (GRI). Para la etapa de medición, se ha inferido sobre la viabilidad de utilizar las unidades de medida propuestas por la GRI. Para la etapa de registro, esta podría ser similar al registro contable tradicional con apoyo de la tecnología.

Se ha seleccionado la GRI porque se vincula los ODS; no así los informes del International Integrated Reporting Council (IIRC), porque consideran la creación de valor. Además, si bien incluyen distintos tipos de capitales, el concepto de 'capital' debería adaptarse al sentido contable para evitar el riesgo de incluir, por "disponibilidad" o tenencia, bienes de terceros (públicos y privados) como activos o componentes del capital del ente que los gestiona sin ser propietario y, con ello, duplicar la existencia de recursos.

En cuanto a la etapa de clasificación se ha concluido sobre la necesidad de adaptar el plan de cuentas con enfoque económico-financiero tradicional para el enfoque socioambiental. Consecuentemente, se ha realizado una adaptación, básica y flexible, a un plan de cuentas tradicional teniendo en cuenta GRI y los ODS. Como dicha adaptación puede ser utilizada para iniciativas relacionadas surgen diversos interrogantes, entre ellos: ¿̇cómo 
contribuir con la comprensión de un plan de cuentas con enfoque contable socioambiental para los ODS? De interpretar al Pacto Global como un punto de inflexión que atraviesa diversas iniciativas y se vincula a los ODS: ¿cómo completar un plan de cuentas contable con enfoque socioambiental para los principios del Pacto Global de Naciones Unidas?

Se entiende que considerar el Pacto Global permite observar la presencia de ciertas configuraciones colectivas hacia los ODS, que las memorias GRI contribuyen a informar los principios del Pacto Global, y que transferir avances sobre el enfoque contable socioambiental enmarcado en los ODS contribuiría a comprender un plan de cuentas para la dimensión social y la ambiental, y no solo centrado en lo financiero.

\section{Objetivos}

Este trabajo tiene por objetivo general intercambiar conocimientos sobre el enfoque socioambiental de la contabilidad social y ambiental enmarcado en los ODS. Constituye el objetivo específico completar un plan de cuentas contable con enfoque socioambiental no financiero para los ODS considerando los principios del Pacto Global de Naciones Unidas.

\section{Metodología}

Esta investigación se define como descriptiva cuasiexperimental, pues se analizan variables pero no se las controla Se plasman en este artículo los avances realizados para el enfoque o perspectiva socioambiental en la especialidad contable social y ambiental. Se selecciona una adaptación efectuada desde un plan de cuentas tradicional hacia la perspectiva socioambiental, teniendo en cuenta las memorias GRI y los ODS, un plan de cuentas para aspectos ambientales, los principios del Pacto Global de Naciones Unidas y ejemplos brindados por la Red Española del Pacto Mundial (2015-2017) de cómo las empresas a través de sus actividades 
apoyan y respetan los diez Principios del Pacto Global o Mundial. Como un camino para construir conocimientos, se realizan análisis inductivos y deductivos que propicien sintetizar los mismos.

Luego, se compara lo constituido con lo constituyente (conceptos y definiciones contables, principios del Pacto Global y el plan de cuentas precedente), que se triangulan con la GRI. Se completa el plan de cuentas seleccionado considerando el enfoque contable socioambiental no financiero.

\section{Marco conceptual}

El Pacto Global de Naciones Unidas surge en 1999 en el Foro Económico de Davos y en el 2000 se lanzó la iniciativa que, puede decirse, atraviesa a los Objetivos de Desarrollo del Mileno y se vincula a los ODS. En sus inicios, los Principios del Pacto Global eran nueve, pero luego pasaron a diez. Según el Pacto Global Red Colombia (Ardila, 2018), los diez Principios universales se relacionan con la Declaración Universal de los Derechos Humanos; la Declaración de los Derechos Laborales, impulsada por la Organización Internacional de Trabajo (OIT); la Declaración de Río de Janeiro sobre el Medio Ambiente, y, en 2004, se incluyó la Convención de la Naciones Unidas contra la Corrupción (p. 3).

En 2015 Naciones Unidas dio a conocer los ODS, que reemplazan los Objetivos de Desarrollo del Milenio. Los ODS son: 1. fin de la pobreza; 2. hambre cero; 3. salud y bienestar; 4. educación de calidad; 5 . igualdad de género; 6. agua limpia y saneamiento; 7. energía asequible y no contaminante; 8. trabajo decente y crecimiento económico; 9. industria, innovación e infraestructura; 10. reducción de las desigualdades; 11. ciudades y comunidades sostenibles; 12. producción y consumo responsables; 13. acción por el clima; 14. vida submarina; 15 . vida de ecosistemas terrestres; 16. paz, justicia e instituciones sólidas; y 17. 
alianzas para lograr los objetivos, los cuales contienen 169 metas (Naciones Unidas, 2015).

El mencionado Pacto Global Red Colombia (2018) permite observar una vinculación entre los principios y los ODS: derechos humanos con el ODS 16; los estándares laborales con los ODS 1, 5, 8 y 10; medio ambiente con los ODS 6, 12 y 13, y anticorrupción con el ODS 16.

En 2020 el Programa de las Naciones Unidas para el Desarrollo y la Cámara de Industria y Comercio Argentino-Alemana emitieron el documento Integridad sostenible: una propuesta de comportamiento empresarial responsable que contribuya al ODS 16 en Argentina, el cual incluye los principios a partir de cuatro "ejes":

\section{Derechos humanos}

- Principio $n .{ }^{0} 1$. Apoyar y respetar la protección de los derechos humanos.

- Principio n. ${ }^{0}$ 2. No ser cómplice de abusos de los derechos.

\section{Ámbito laboral}

- Principio n. ${ }^{\circ}$ 3. Apoyar los principios de la libertad de asociación sindical y el derecho a la negociación colectiva.

- Principio n. ${ }^{\circ} 4$. Eliminar el trabajo forzoso y obligatorio.

- Principio n. ${ }^{0} 5$. Abolir cualquier forma de trabajo infantil.

- Principio n. ${ }^{\circ}$ 6. Eliminar la discriminación en materia de empleo y ocupación.

\section{Medio ambiente}

- Principio n. ${ }^{\circ}$ 7. Las empresas deberán mantener un enfoque preventivo que favorezca el medio ambiente.

- Principio n. ${ }^{\circ}$ 8. Las empresas deben fomentar las iniciativas que promuevan una mayor responsabilidad ambiental.

- Principio n. ${ }^{\circ}$ 9. Las empresas deben favorecer el desarrollo y la difusión de las tecnologías respetuosas con el medio ambiente.

\section{Anticorrupción}


- Principio n. ${ }^{0}$ 10. Las empresas e instituciones deberán trabajar contra la corrupción en todas sus formas, incluidos extorsión y soborno. (Programa de Naciones Unidas para el Desarrollo, 2020, p. 4)

Desde lo contable, es posible brindar información económica, financiera, social y ambiental de un buen comportamiento en materia de responsabilidad social. La óptica contable económico-financiera permite diferenciar lo económico de lo financiero; es una perspectiva de análisis y una propuesta de informes contables homogéneos sobre el patrimonio de las organizaciones económicas, sus variaciones, algunos riesgos y bienes de terceros. Contablemente, aspectos sociales y ambientales pueden ser analizados bajo el enfoque económico-financiero y también bajo el enfoque socioambiental, que contribuye a brindar información no financiera. Si bien es necesario acordar normas para la emisión de informes contables sociales y ambientales homogéneos con información no financiera, aspectos contenidos en el marco conceptual de la Fundación de Estándares Internacionales de Reportes Financieros (IFRS) (2018) pueden ser bases para aquellas, adicionando la diferencia entre patrimonio y patrimonio neto.

Para Pahlen la contabilidad social y ambiental es un segmento contable que procura "medir en términos diferentes a lo que sugiere la economía pues las metas sociales, tanto macro- como micro-, exceden el reduccionismo economicista, [...] el registro y medición de los recursos naturales y el impacto económico vinculado a la sostenibilidad del medio ambiente" (2017, p. 7). Entiende que se "refiere a los objetivos sociales producto de teorías sociológicas y temas medioambientales” (p. 7). Pero el enfoque socioambiental puede considerarse complementario del económico-financiero tradicional. Es otra perspectiva de análisis e información de la realidad de las organizaciones económicas que 
(respetando la especificidad contable) permite adaptar para la sostenibilidad las variables relevantes de lo contable y propicia el uso de diversas unidades de medida, el capital social y ambiental mínimo por mantener y la aplicación de instrumentos por medio del proceso contable tradicional.

El enfoque socioambiental no financiero contribuye a relacionar y a adaptar conocimientos contables consensuados desde lo económicofinanciero hacia la sostenibilidad, considerando activos, pasivos y patrimonio neto sociales y ambientales. El enfoque socioambiental favorece una visión holística y para la cual es necesaria la utilización de distintas unidades de medida.

Se reconoce como objetivo de la contabilidad socioambiental: "Obtener y brindar conocimiento racional de la dimensión socioambiental considerada, es decir del patrimonio socioambiental, los impactos socioambientales y sus relaciones, no meramente financieros, en el ente, sujeto del proceso, y en su entorno [...] (Geba et al., 2007, p. 9). Geba y Bifaretti (2017) concluyen "que en el marco de la especialidad contable socioambiental [...] al diferenciar el Activo, el Pasivo y el Patrimonio Neto socioambientales, es posible identificar la fuente de los Activos socioambientales que se originan por los aportes de los propietarios de la organización [de los] autogenerados por esta (impactos socioambientales positivos menos impactos socioambientales negativos).” (pp. 20-21). El proceso contable de datos, podría contribuir "a poner en relevancia cuestiones de capital social y ambiental, de manera integrada a la información contable financiera tradicional, en momentos y lugares determinados y diferenciando los impactos sociales de los naturales del ente y de su entorno, en un ejercicio económico y de manera comparativa con ejercicios anteriores" (p. 21). 
De sucesivas investigaciones se rescata que:

En la dinámica cotidiana del proceso contable, de manera implícita o explícita, los conocimientos doctrinarios (base de las normativas contables) y las normas contables profesionales, nacionales e internacionales (referidas a valuación/medición, exposición y otras) enmarcan modelos de informes contables homogéneos destinados a usuarios internos y externos de una organización. (Geba, Bifaretti, Rovelli y Pascuzzi Rey, 2019, p. 9)

Se interpreta que:

El Proceso contable, con sus sub-procesos y etapas componentes, es un proceso metódico, sistemático y evaluable que puede contribuir a identificar un punto de partida para medir y valorar impactos y dependencias sobre el capital social y natural (además del Activo y Pasivo sociales y naturales), con un sentido objetivo y claro. Podría tener en cuenta la materialidad, prioridades específicas de la industria, prioridades locales y nacionales. (Geba y Bifaretti, 2017, p. 21).

Para clasificar, medir, registrar e informar los componentes del patrimonio de los entes, sus variaciones, bienes de terceros y contingencias, en el proceso contable se utilizan las cuentas. Para Fernández Lorenzo (2013) se denominan cuentas a los

[...] conjuntos de elementos homogéneos, referidos a la composición del patrimonio de un ente y sus variaciones. Estos elementos se comportan de manera similar respecto de la igualdad fundamental contable. [Por medio] de las cuentas se crea un lenguaje contable para representar el patrimonio de los entes de forma cualitativa y cuantitativa; describir sus variaciones y las causas [...]; procesar los datos antes mencionados, y elaborar informes al respecto. [...] La cuenta es una herramienta fundamental del proceso contable. 
- Representar el patrimonio de los entes de forma cualitativa y cuantitativa;

- Describir sus variaciones y las causas [...];

- Procesar los datos antes mencionados; y

- Elaborar informes al respecto.

- La cuenta es una herramienta fundamental del proceso contable [...]. (2013, p. 91)

Es posible para el enfoque socioambiental contable determinar que, una vez captados los datos, se los agrupa en una cuenta que según su naturaleza pueden ser clasificados como cuentas patrimoniales socioambientales (de activo, pasivo y patrimonio neto), de resultado y de orden socioambientales (deudoras y acreedoras). Las cuentas de resultado socioambiental pueden ser positivas o negativas según su incidencia cuantitativa en el patrimonio neto socioambiental; se pueden originar en la gestión del ente (internos) o del contexto (externos). Deberían diferenciarse los ingresos, los costos consumidos, los gastos, las ganancias y las pérdidas socioambientales, sean o no significativos. A su vez, pueden generase en el ejercicio o en ejercicios anteriores, y como operativos o no operativos y ordinarios o extraordinarios, entre otros (Geba, 2019, pp. 189, 190).

También puede rescatarse que:

Por su extensión, grado de detalle, o contenido relacionado con la variable temporal, las cuentas patrimoniales socio-ambientales pueden agrupar varias cuentas menores y clasificarse como: Recompuestas (activo, pasivo, patrimonio neto socio-ambientales), compuestas (activo corriente y activo no corriente o pasivo corriente y pasivo no corriente socio-ambientales), complejas o "rubros" que permiten relacionar 
naturaleza, variable temporal, objeto del ente y forma jurídica (inversiones, créditos, bienes de cambio, bienes de uso, activos intangibles, deudas ambientales, deudas sociales, otras, capital socioambiental y resultados acumulados no asignados socio-ambientales) [...]. (Geba, 2019, p.190)

Más analíticamente pueden considerarse cuentas sintéticas los materiales, energía, agua, emisiones de GEI aprobadas, puestos de trabajo programados, residuos aprobados, vertido de agua aprobado, proveedores, acreedores y otras, las cuales componen los rubros pertinentes. También es posible generar cuentas analíticas o individuales para particularizar los contenidos de las cuentas sintéticas, tales como puestos de trabajo altos ejecutivos locales, puestos de trabajo altos ejecutivos no locales, puestos de trabajo empleados locales, puestos de trabajo empleados no locales, puestos de trabajo trabajadores locales, puestos de trabajo trabajadores no locales, materiales renovables, materiales no renovables, energía generada, energía comprada, agua adquirida, agua reciclada. A su vez, para mayor grado de detalle cada puesto de trabajo puede ser identificado por grupo etario y por género, entre otras. Las cuentas de resultado socio-ambiental deben permitir reflejar las causas de las variaciones cuantitativas en el patrimonio neto que no provienen ni de aportes ni retiros de los propietarios, las cuales pueden agruparse como resultados positivos y negativos, operativos o no operativos, ordinarios y extraordinarios, entre otros (Geba, 2019, p.190).

Las cuentas utilizadas por las organizaciones económicas se encuentran en los denominados planes de cuentas. "El plan de cuentas es el ordenamiento metódico y sistemático de todas las cuentas del sistema contable para el logro de sus fines" (Fernández Lorenzo, 2013, p. 94). Las instrucciones para su uso y control se encuentran en los manuales de cuentas: "Dentro de parámetros homogéneos, cada organización 
económica elabora su Plan y Manual de cuentas, para lo cual en algunos casos necesitan del apoyo de expertos pertinentes" (Geba, 2019, p. 191).

\section{Desarrollo}

Según la IFRS (2019), quienes han participado en el Diálogo de Informes Corporativos, "identifican la transparencia y la rendición de cuentas como fundamentales para lograr mecanismos de gobernanza de alta calidad y el empoderamiento de las partes interesadas en las sociedades y los mercados modernos". Amerita considerar que:

En el documento titulado "Comprender el valor de la transparencia y la rendición de cuentas", CDP, el Consejo de Normas de Divulgación Climática, la Iniciativa Global de Informes, la Junta Internacional de Normas de Contabilidad, el Consejo Internacional de Informes Integrados, la Organización Internacional de Normalización y el Consejo de Normas de Contabilidad de Sostenibilidad establecen siete principios de transparencia y rendición de cuentas que comúnmente creen que son fundamentales para la presentación de informes corporativos: materialidad, integridad, exactitud, equilibrio, claridad, comparabilidad y fiabilidad. (Consejo Internacional Integrado de Información, 2019).

Para este desarrollo se tienen en cuenta aspectos del marco conceptual de la IFRS (2018), la Norma Internacional de Contabilidad (NIC) 1, y conceptos y definiciones considerados para que, junto con los principios del Pacto Global, se complete un plan de cuentas socioambiental seleccionado.

Para la perspectiva socioambiental no financiera pueden respetarse cuestiones relevantes del Marco Conceptual de la IFRS (2018). Al omitir o reemplazar específicas y generalizables referencias a lo financiero es factible ampliar el sentido de lo expresado, considerando cuestiones tales como que la información socioambiental no financiera útil “[...] debe ser 
relevante y representar fielmente lo que pretende representar", la utilidad de la información socioambiental se mejora si es comparable, verificable, oportuna y comprensible (p. 15).

La información socio-ambiental relevante tiene que ser capaz de hacer una diferencia en las decisiones de los usuarios. La información socioambiental

[...] es capaz de hacer una diferencia en las decisiones si tiene valor predictivo, valor de confirmación o ambos. [...]tiene un valor predictivo si se puede utilizar como una entrada para procesos empleados por los usuarios para predecir los resultados futuros [y] no necesita ser una predicción o pronóstico para tener un valor predictivo [...]. Tiene un valor confirmatorio si proporciona retroalimentación sobre (confirma o cambia) las evaluaciones previas. El valor predictivo y el confirmatorio están interrelacionados. La información que tiene un valor predictivo a menudo también tiene un valor confirmatorio. (IFRS, 2018, pp. 15-16)

En relación con la materialidad, la "información es importante si omitirla o indicarla incorrectamente podría influir en las decisiones que toman los usuarios principales [...]”. Para ser útil, la información socioambiental debe representar fielmente fenómenos relevantes y la sustancia de los fenómenos que pretende representar. Así mismo:

[Una] descripción completa de un grupo de activos incluiría, como mínimo, una descripción de la naturaleza de los activos en el grupo, una representación numérica de todos los activos en el grupo, y una descripción de la descripción numérica [...] En algunos ítems, una descripción completa también puede incluir explicaciones de hechos significativos sobre la calidad y naturaleza de los ítems, factores y circunstancias que pueden afectar su calidad y naturaleza, y el proceso utilizado para determinar la representación numérica. (pp. 16-17)

Una representación es neutral, si no está sesgada, sin énfasis o manipulada. Esto no significa que la información neutral no tenga 
propósito o influencia en el comportamiento. El ejercicio de la prudencia apoya la neutralidad. Por su parte, la comparabilidad "permite a los usuarios identificar y comprender similitudes y diferencias entre los elementos. A diferencia de las otras características cualitativas [...], no se relaciona con un solo elemento. Una comparación requiere al menos dos elementos" (p. 19). Probablemente se alcance cierto grado de comparabilidad al satisfacer las características cualitativas fundamentales: "Una representación fiel de un fenómeno... relevante debe poseer naturalmente algún grado de comparabilidad con una representación fiel de un fenómeno [...] relevante similar por parte de otra entidad que informa" (pp. 19-20).

Así mismo, la verificabilidad ayuda a asegurar; esto significa que puede constatarse. En la verificación directa se comprueba la información a través de la observación directa una cantidad u otra representación, mientras que la "verificación indirecta significa verificar las entradas a un modelo, fórmula u otra técnica y volver a calcular las salidas usando la misma metodología”. Algunas explicaciones e información prospectiva pueden no ser verificadas sino hasta un período futuro (p. 20), generalmente sería necesario revelar las suposiciones subyacentes, los métodos de compilación y otros factores. En relación a dichas cuestiones, se ha expresado que:

Dentro del modelo de la contabilidad social y ambiental con enfoque socioambiental es recomendable considerar el postulado de Equidad, así como los principios contables de ente, bienes económicos, empresa en marcha, ejercicio, objetividad, realización, devengado, prudencia, uniformidad, materialidad y exposición.

Para la medición pueden utilizarse distintas unidades de medida pertinentes, incluida la monetaria, y la registración realizarse en registros adecuados al efecto que permitan sistematizar los datos, 
obtener y emitir información periódica que sea metódica, mayormente cuantificada y evaluable, útil para la organización económica, para otras organizaciones económicas y para la sociedad en su conjunto. (Geba, Bifaretti y Rovelli, 2020, p. 14)

De manera similar, podría adaptarse, entre otras, la Norma Internacional de Contabilidad (NIC) 1 Presentación de Estados Financieros para la Presentación de Estados No Financieros. En ella se establece requerimientos generales para su presentación, guías para determinar su estructura y requisitos mínimos de contenido. Pueden considerarse, entre otros la materialidad, la hipótesis de negocio en marcha y base contable de acumulación (o devengo).

En la materialidad (o importancia relativa), los estados suministran información de una entidad sobre activos, pasivos, patrimonio, ingresos y gastos, en los cuales se incluyen las ganancias y pérdidas, aportaciones de los propietarios y las distribuciones en su condición de tales (aunque debería diferenciar patrimonio de patrimonio neto). Las notas brindan "descripciones narrativas o desagregaciones de partidas presentadas en esos estados e información sobre partidas que no cumplen las condiciones para ser reconocidas en ellos” (IFRS, p. 9).

Con la hipótesis de negocio en marcha, la gerencia debe evaluar "la capacidad que tiene la entidad para continuar en funcionamiento", cuando, al realizar esta evaluación, la gerencia "sea consciente de la existencia de incertidumbres importantes, relativas a eventos o condiciones que puedan aportar dudas significativas sobre la posibilidad de que la entidad siga funcionando normalmente, procederá a revelarlas" (p. 13).

Se utiliza la "base contable de acumulación (o devengo)" para la materialidad o importancia relativa y agrupación de datos: "Cada clase de 
partidas similares, que posea la suficiente importancia relativa, deberá ser

presentada por separado [...] a menos que no sean materiales" (p. 14). No

pueden compensarse activos con pasivos o ingresos con gastos, a menos

que se requiera o se permita por una "norma", por lo cual se informarán

por separado todas estas categorías.

Tabla 1. Activo con enfoque económico-financiero y socioambiental

\begin{tabular}{|c|c|c|}
\hline $\begin{array}{l}\text { Económico-financiero } \\
\text { Activo económico-financiero }\end{array}$ & $\begin{array}{l}\text { Ambiental-natural } \\
\text { Activo natural }\end{array}$ & $\begin{array}{l}\text { Social-sociedad } \\
\text { Activo social }\end{array}$ \\
\hline $\begin{array}{l}\text { "Un activo es un recurso } \\
\text { económico presente } \\
\text { controlado por la entidad } \\
\text { como resultado de sucesos } \\
\text { pasados. Un recurso } \\
\text { económico es un derecho } \\
\text { que tiene el potencial de } \\
\text { producir beneficios } \\
\text { económicos". (IFRS } \\
\text { Foundation, 2015, p. 33)* } \\
\text { "Un activo es un recurso } \\
\text { económico presente } \\
\text { controlado por la entidad } \\
\text { como resultado de eventos } \\
\text { pasados [...] Un recurso } \\
\text { económico es un derecho } \\
\text { que tiene el potencial de } \\
\text { producir beneficios } \\
\text { económicos". (IFRS, 2018, } \\
\text { p. 28)* }\end{array}$ & $\begin{array}{l}\text { "No dependería de su tangibilidad, de la forma de } \\
\text { adquisición, de la posibilidad de venderlo por separado, de } \\
\text { la erogación previa de un costo. Es decir, un elemento } \\
\text { activo natural haría referencia a bienes y servicios } \\
\text { ambientales, o stocks de la naturaleza que producen una } \\
\text { renta natural, o flujo de bienes y servicios que son útiles } \\
\text { (p.ej.: una población de árboles que autogenera nuevos } \\
\text { árboles y otros servicios ecosistémicos - de soporte y } \\
\text { estructuras, de regulación atmosférica, climática, hídrica, } \\
\text { formación del suelo, regulación de nutrientes, control } \\
\text { biológico y culturales como la mejora emocional y } \\
\text { percepción), incorporado al patrimonio (por compra, } \\
\text { donación recibida, aporte de los propietarios, } \\
\text { autogeneración, otras), con o sin erogación previa. } \\
\text { Asimismo, la posibilidad de flujos positivos de un activo } \\
\text { natural debería estar asegurada con certeza (ciertos) o } \\
\text { esperada con un alto grado de probabilidad (probables), } \\
\text { pudiendo ser directa o indirecta.[...] en este modelo } \\
\text { también se internaliza que, como en XXX CIC (2013), } \\
\text { múltiples hechos ambientales suceden fuera de los } \\
\text { mercados y 'no necesariamente su valor se puede expresar } \\
\text { en términos monetarios', y, consecuentemente, incluye } \\
\text { distintas unidades de medida, indicadores simples y } \\
\text { complejos, pertinentes [...] Adicionalmente, debería } \\
\text { emitirse en la información complementaria la composición } \\
\text { de los rubros, así como el grado de incertidumbre asociado } \\
\text { al proceso de medición de flujos futuros netos esperados } \\
\text { en función de la naturaleza, con y sin intervención } \\
\text { humana". (Geba, Bifaretti y Sebastián, 2013, p. 18) } \\
\text { "Los activos naturales comprenderían, cuando } \\
\text { correspondan, aspectos del agua, la tierra, el aire, } \\
\text { biodiversidad, otros". (Geba y Gastañaga, 2014, p. 7) }\end{array}$ & $\begin{array}{l}\text { "No debería } \\
\text { depender de su } \\
\text { tangibilidad, ni de } \\
\text { la forma de } \\
\text { adquisición, ni de } \\
\text { la posibilidad de } \\
\text { venderlo por } \\
\text { separado, ni de la } \\
\text { erogación previa } \\
\text { de un costo. Es } \\
\text { decir, un } \\
\text { elemento activo } \\
\text { social haría } \\
\text { referencia a } \\
\text { bienes y servicios } \\
\text { sociales en } \\
\text { concordancia con } \\
\text { la } \\
\text { responsabilidad } \\
\text { social de la } \\
\text { organización, la } \\
\text { riqueza social o el } \\
\text { grado de } \\
\text { desarrollo social } \\
\text { de una } \\
\text { comunidad". } \\
\text { (Bifaretti y } \\
\text { Catani, 2015, } \\
\text { p. 18) }\end{array}$ \\
\hline
\end{tabular}

* De una traducción libre realizada por Wilmar Franco Franco para propósitos

académicos.

Fuente: elaboración propia con base en Geba et al. (2016).

Revista Activos

ISSN: 0124-5805 | e-ISSN: 2500-5278 | DOI: https://doi.org/10.15332/25005278

Vol. 19 N.o 1 | enero-junio de 2021 
El plan de cuentas adaptado para lo socioambiental que se selecciona respeta la sistematicidad de los planes de cuentas tradicionales, considera una actividad a modo de ejemplo e incluye cuentas recompuestas, compuestas y complejas. En la tabla 1 se describe el activo, para el plan de cuentas.

Lo interpretado como activo social podría contener los principios del Pacto Global de Naciones Unidas en sus ejes: derechos humanos, ámbito laboral y anticorrupción. Pueden ser considerados como activo social mientras hagan referencia a bienes y servicios sociales en concordancia con la responsabilidad social asumida por la organización. Como activos, estos bienes y servicios sociales pueden ser interpretados como recursos sociales del ente como resultado de eventos pasados y con el potencial de generar beneficios sociales para la organización y el contexto.

Podrían clasificarse como activos intangibles: "Los puestos de trabajo, su tipo y características, por interpretar que constituyen un intangible del ente el derecho a recibir los servicios contratados que incluyen conocimientos y experiencias adquiridos, contribuyendo a generar "riqueza”, favoreciendo al ente y su contexto" (Geba, 2019, p. 193). Como inversiones sociales debe entenderse que "no es el sujeto quien corresponde al ente, es la cualidad otorgada de 'personal capacitado' la que permite obtener o mejorar ingresos" (Geba, 2019, p. 193), los bienes o servicios sociales, como también la salud, la no discriminación, la anticorrupción y similares.

En cuanto al eje de medio ambiente podrían reconocerse como activo ambiental las iniciativas para mantener un enfoque preventivo que favorezca el medio ambiente, para promover una mayor responsabilidad ambiental y favorecer el desarrollo y la difusión de las tecnologías respetuosas con el medio ambiente cuando, como bienes y servicios 
ambientales, puedan producir beneficios ambientales, o flujos

ambientales, útiles para el ente y el contexto. Se diferencian en los bienes

de cambio, "los materiales renovables de los que no lo son, los insumos

reciclados, los combustibles, la energía y el agua y sus fuentes, entre otros, por medio de cuentas sintéticas y analíticas" (Geba, 2019, p. 193), cuando

hagan a la actividad del ente. Para créditos sociales y ambientales, si la evaluación ambiental es necesaria para habilitar el proyecto o la actividad, es posible incluir, ya sea en el momento inicial como en sus renovaciones o actualizaciones, los puestos de trabajo programados o comprometidos, así como sus tipos, y los derechos "de emisiones, residuos, vertidos de agua, otros, aprobados y necesarios para desarrollar la actividad [...] permitiendo conocer el capital socio-ambiental aportado, los límites y, luego, los defectos o excesos por variaciones, impactos, en el periodo" (p. 193). En la tabla 2 se describe el pasivo desde los dos enfoques de interés.

Tabla 2. Pasivo con enfoque económico-financiero y socio-ambiental

\begin{tabular}{|c|c|c|}
\hline \multicolumn{3}{|c|}{ Especialidad económico-financiera $\longleftrightarrow \longrightarrow$ especialidad socio-ambiental } \\
\hline Económico-financiero & Ambiental-natural & Social-sociedad \\
\hline $\begin{array}{l}\text { "Pasivo es una obligación presente de la } \\
\text { entidad de transferir un recurso } \\
\text { económico como resultado de sucesos } \\
\text { pasados." (IFRS Foundation, 2015, p. 33). } \\
\text { Se aclara que la definición de pasivo hace } \\
\text { referencia a una "obligación presente". Se } \\
\text { propone que una "entidad tiene una } \\
\text { obligación presente de transferir un } \\
\text { recurso económico si: (a) la entidad no } \\
\text { tiene capacidad práctica de evitar la } \\
\text { transferencia; y (b) la obligación ha surgido } \\
\text { de sucesos pasados; en otras palabras, la } \\
\text { entidad ha recibido los beneficios } \\
\text { económicos, o llevado a cabo las } \\
\text { actividades, que establecen la medida de } \\
\text { su obligación" (p. 37)*. } \\
\text { "Para que exista un pasivo, se deben } \\
\text { cumplir tres criterios: a) la entidad tiene } \\
\text { una obligación [...]; b) la obligación es } \\
\text { transferir un recurso económico [...]; y c) la } \\
\text { obligación es una obligación presente que }\end{array}$ & $\begin{array}{l}\text { "Estaría conformado cuando por un } \\
\text { hecho ocurrido el ente está obligado } \\
\text { a entregar activos o prestar servicios, } \\
\text { o es altamente probable que ello } \\
\text { ocurra, y su cancelación es ineludible. } \\
\text { Abarcaría las obligaciones legales } \\
\text { como las asumidas voluntariamente, } \\
\text { cuando del comportamiento del ente } \\
\text { puede deducirse que aceptará ciertas } \\
\text { responsabilidades frente a terceros, } \\
\text { creando expectativas de que } \\
\text { cancelará esa obligación mediante la } \\
\text { entrega de activos o la prestación de } \\
\text { servicios [...] de rescatar que en el } \\
\text { marco del desarrollo sustentable se } \\
\text { 'apunta' a minimizar el pasivo } \\
\text { ambiental o, por lo menos a evitar } \\
\text { que se incremente, el pasivo } \\
\text { ambiental podría estar generado por } \\
\text { [obligaciones normativas o } \\
\text { compromisos asumidos para evitar } \\
\text { daños ambientales] (contaminación }\end{array}$ & $\begin{array}{l}\text { "podría estar } \\
\text { conformado } \\
\text { cuando por un } \\
\text { hecho anterior el } \\
\text { ente está } \\
\text { obligado } \\
\text { (legalmente o } \\
\text { voluntariamente } \\
\text { al aceptar } \\
\text { determinadas } \\
\text { responsabilidades } \\
\text { hacia terceros) a } \\
\text { transferir activos } \\
\text { o prestar } \\
\text { servicios, o es } \\
\text { altamente } \\
\text { probable que así } \\
\text { sea y su } \\
\text { cancelación no } \\
\text { puede eludirse". } \\
\text { (Bifaretti y }\end{array}$ \\
\hline
\end{tabular}




\begin{tabular}{|c|c|c|}
\hline \multicolumn{3}{|c|}{ Especialidad económico-financiera $\longleftrightarrow \longrightarrow$ especialidad socio-ambiental } \\
\hline Económico-financiero & Ambiental-natural & Social-sociedad \\
\hline $\begin{array}{l}\text { existe como resultado de eventos } \\
\text { pasados" [...] (IFRS, 2018, p. 32). } \\
\text { "Muchas obligaciones se establecen por } \\
\text { contrato, legislación o medios similares y } \\
\text { son jurídicamente exigibles por la parte (o } \\
\text { partes) a quienes se les debe. Las } \\
\text { obligaciones también pueden surgir [...] de } \\
\text { las prácticas consuetudinarias de una } \\
\text { entidad, políticas publicadas o } \\
\text { declaraciones específicas... La obligación } \\
\text { que surge en tales situaciones a veces se } \\
\text { denomina 'obligación implícita' [...]. } \\
\text { [...] En algunas situaciones, el deber o la } \\
\text { responsabilidad de una entidad de } \\
\text { transferir un recurso económico está } \\
\text { condicionado a una acción futura } \\
\text { particular que la propia entidad pueda } \\
\text { tomar. Tales acciones podrían incluir } \\
\text { operar un negocio en particular u operar } \\
\text { en un mercado particular en una fecha } \\
\text { futura específica, o ejercer opciones } \\
\text { particulares dentro de un contrato. En } \\
\text { tales situaciones, la entidad tiene una } \\
\text { obligación si no tiene la capacidad práctica } \\
\text { de evitar tomar esa acción” (p. 33). }\end{array}$ & $\begin{array}{l}\text { del agua, del suelo, del aire, deterioro } \\
\text { de los recursos y de los ecosistemas, } \\
\text { otros) producidos por un hecho } \\
\text { anterior y que superen [o no] los } \\
\text { límites para mantener un } \\
\text { determinado equilibrio ecosistémico, } \\
\text { el que podría estar determinado por } \\
\text { procedimientos de evaluación de } \\
\text { impacto ambiental previos y referidos } \\
\text { a los daños ambientales generados, o } \\
\text { a generar, que representen un daño o } \\
\text { un riesgo actual o potencial } \\
\text { significativo. Cuantitativamente, se } \\
\text { podrían utilizar distintas unidades de } \\
\text { medida, indicadores simples y } \\
\text { complejos, pertinentes [...] los pasivos } \\
\text { naturales podrían incluir la dimensión } \\
\text { natural comprometida (agua, tierra, } \\
\text { aire, biodiversidad, otras), y como } \\
\text { pasivo corriente o no corriente según } \\
\text { corresponda. Adicionalmente, debería } \\
\text { emitirse en la información } \\
\text { complementaria la composición de } \\
\text { los rubros, así como el grado de } \\
\text { incertidumbre asociado al proceso de } \\
\text { medición". (Geba et ál., 2013, p. 18) }\end{array}$ & $\begin{array}{l}\text { Catani, 2015, } \\
\text { p. 18) }\end{array}$ \\
\hline
\end{tabular}

* De una traducción libre realizada por Wilmar Franco Franco para propósitos académicos.

Fuente: Geba et al. (2016)

El pasivo con enfoque socioambiental puede estar conformado por compromisos asumidos u obligaciones socioambientales (ciertas y probables), cuantificadas, o cuantificables de manera objetiva, en distintas unidades de medida pertinentes. Deberían considerarse previsiones de pasivo cuando, por un hecho, acto o circunstancia generado en el ejercicio, existiera una alta probabilidad (riesgo) de perfeccionarse como pasivo cierto en el futuro.

Es apropiado que, al cierre del ejercicio, se registren como resultado negativo las disminuciones en los activos sociales y ambientales por pérdidas o disminuciones de su capacidad de satisfacer necesidades, ya sea 
por el transcurso del tiempo, agotamiento, obsolescencia y similares, así como por fenómenos naturales.

Con tales consideraciones, Geba (2019) describe los resultados positivos y negativos de la siguiente manera:

[...] resultados positivos socioambientales el reciclado o recuperación de materiales, de insumos, de agua, la generación de energía y la formación, así como la contratación de personal que excede la cantidad comprometida al inicio [que aumentan el patrimonio neto socioambiental]. Se entiende como resultados negativos socioambientales a los consumos de costos y a los gastos (no como sinónimo de pago), así como la baja de personal, entre otros [que disminuyen el patrimonio neto socioambiental]. (p. 193)

Sobre capital social y ambiental con enfoque socioambiental, Geba et al. (2020) afirman que:

Considerar desde lo contable el capital social y ambiental, puede contribuir a configurar colectivamente que la salud y la capacitación de la población, así como los recursos naturales y su cuidado y preservación, son activos necesarios para la vida y no constituyen un gasto. La consideración como activos del ente propendería a conocer el origen, la naturaleza, la ubicación, la propiedad y el control de recursos sociales y ambientales, así como las obligaciones, evitando algunos riesgos del denominado "lavado ecológico", desde lo significado como lavado de activos. (Geba et al., 2020, p. 14).

Con enfoque socioambiental,

[...] el Patrimonio Neto socio-ambiental incluiría un capital socioambiental mínimo a mantener (aporte de los propietarios) teniendo en cuenta características del ente y su contexto, que puede ser inclusivo del compromiso organizacional con las metas de los ODS, y los 
resultados positivos y negativos generados y acumulados por la organización. (Geba y Bifaretti, 2017, p. 21)

Podrían diferenciarse el capital socioambiental interno mínimo por mantener del externo al ente, o de su entorno:

[La cuantía de dicho] capital socioambiental externo mínimo a mantener, puede surgir de compromisos de los propietarios con sus stakeholders y de disposiciones legales nacionales, regionales o municipales, que tengan en cuenta el tipo de ecosistema, capacidades y vulnerabilidades de los mismos, así como el grado de desarrollo social, sus necesidades y capacidades. Y, respecto de la unidad de medida... podrían utilizarse distintas unidades de medida pertinentes, indicadores cualitativos y cuantitativos, simples y complejos”. (Geba y Bifaretti, 2017, p. 21)

De los ejemplos brindados por Global Compact, Pacto Mundial Red Española (2015a-h; 2017a,b) de cómo las empresas a través de sus actividades pueden apoyar y respetar los Principios del Pacto Global o Mundial, se rescatan los siguientes:

En derechos humanos, principio 1: "Las empresas deben apoyar y respetar la protección de los derechos humanos fundamentales, reconocidos internacionalmente, dentro de su ámbito de influencia”, considera el lugar de trabajo: proporcionar condiciones de trabajo saludables y seguras, garantizar la libertad de asociarse, brindar acceso a la salud básica, a la educación y a la vivienda para los trabajadores y sus familias, cuando no se les da otro lugar; poseer un programa de acción para impulsar la contratación de víctimas de violencia doméstica; hacer ajustes razonables para adaptarse a las prácticas religiosas de los empleados"; y en la comunidad: prevenir el desplazamiento forzoso de individuos, de grupos o comunidades; asegurar el respeto a las directrices y estándares internacionales vigentes para el uso de la fuerza cuando las empresas usan 
servicios de seguridad para proteger sus operaciones (Un Global Compact Red Española del Pacto Mundial, 2017a).

Para derechos humanos, principio 2: "Las empresas deben asegurarse de que sus empresas no son cómplices en la vulneración de los Derechos Humanos”. En 2017 incluye: identificar funciones en la organización con mayor riesgo de vincularse con los abusos contra los derechos humanos y riesgos funcionales internos en posteriores a la inversión; en la comunidad o región, evaluar el impacto sobre derechos humanos que una inversión pueda causar (Global Compact Red Española del Pacto Mundial, 2017b).

Sobre normas laborales, principio 3: "Las empresas deben apoyar la libertad de afiliación y el reconocimiento efectivo del derecho a la negociación colectiva", considera en el lugar del trabajo: respetar el derecho de los trabajadores a formar y afiliarse al sindicato que elijan sin temor a represalia o intimidación, conforme a la legislación nacional; brindar a los representantes de los trabajadores instalaciones apropiadas para ayudar al desarrollo del convenio colectivo; en la mesa de negociación: para fines de negociación colectiva, reconocer a las organizaciones representativas; y en la comunidad de la operación: especialmente en países que no tienen un adecuado marco institucional o legal, tomar medidas que mejoren el clima de las relaciones laborales. (Un Global Compact Red Española del Pacto Mundial, 2015a).

Para normas laborales, principio 4: "Las empresas deben apoyar la eliminación de toda forma de trabajo forzoso o realizado bajo coacción”, es necesario para las organizaciones determinar si el trabajo forzoso es un riesgo de sus operaciones y de su sector empresarial. El primer paso para adoptar medidas para combatir el trabajo forzoso es comprender sus causas, las personas perjudicadas deben ser retiradas del trabajo y de las instalaciones cuando es identificado el trabajo forzoso. Las empresas pueden en el lugar del trabajo: tener en cuenta las normas internacionales 
cuando es insuficiente el cumplimiento de las disposiciones laborales de las leyes y reglamentos nacionales; indicar en los contratos de trabajo los términos y condiciones del servicio, la libertad de salir y los procedimientos apropiados, el carácter voluntario del empleo, también las sanciones asociadas por el cese o salida del trabajo y que es importante vigilar con cuidado los acuerdos de subcontratación y las cadenas de suministro; en la comunidad de operación: para desarrollar un enfoque conjunto de la industria sobre el tema, y construir puentes con sindicatos, autoridades policiales, inspecciones de trabajo, otras, trabajar en alianza con otras empresas, asociaciones sectoriales y organizaciones empresariales; apoyar y contribuir a los modelos de educación, de formación profesional y de asesoramiento para niños que han sido retirados de situaciones de trabajo forzoso; para adultos que han sido apartados de la actividad de trabajo forzoso, colaborar con el desarrollo de la formación profesional y alternativas de generación de ingresos, incluidos los programas de financiación de microcréditos; y para los trabajadores apartados del trabajo forzoso peligroso promover programas de salud y nutrición complementaria y proporcionar atención médica para auxiliar a los afectados por malnutrición y enfermedades profesionales por su trabajo involuntario. (Un Global Compact Red Española del Pacto Mundial, 2015b).

En normas laborales, principio 5: "Las empresas deben apoyar la erradicación del trabajo infantil”, entienden como algunos ejemplos para las empresas en el lugar de trabajo: tener en cuenta las normas internacionales, cuando la legislación nacional es insuficiente, se adhieren a la edad de admisión de reglamentos y leyes nacionales de trabajo; adoptar medidas que garanticen que los salarios a los adultos tienen en cuenta sus necesidades y las de sus familias cuando los salarios no se determinan de forma colectiva o por regulación del salario mínimo. En la 
comunidad: para desarrollar un enfoque de la industria en el abordaje de la cuestión y construir puentes con sindicatos, autoridades policiales, inspecciones de trabajo y demás, trabajar en asociación con otras empresas, con asociaciones sectoriales y organizaciones empresariales; en la organización de empleadores que sea representativa local, estatal o nacional, participar o establecer un grupo de trabajo o comité sobre trabajo infantil (Un Global Compact Red Española del Pacto Mundial, 2015c).

Sobre ]normas laborales, principio 6: "Las empresas deben apoyar la abolición de las prácticas de discriminación en el empleo y la ocupación" expresan los siguientes ejemplos en el lugar de trabajo: tener registros actualizados sobre el reclutamiento, la capacitación y la promoción para brindar una visión transparente de oportunidades para los empleados y su promoción en la organización; al personal brindarle capacitación sobre políticas y prácticas de no discriminación, incluyendo la conciencia de la discapacidad; ajustar o adecuar de manera razonable el entorno físico a efectos de garantizar la salud y la seguridad de empleados, de clientes y de otros visitantes con discapacidad"; en la comunidad: "Garantizar la igualdad de acceso al empleo de las mujeres y las minorías." (Un Global Compact Red Española del Pacto Mundial, 2015d).

Para medioambiente, principio 7: "Las empresas deberán mantener un enfoque preventivo que favorezca el medio ambiente", ejemplifican: “Apoyar la investigación científica, incluyendo la investigación independiente y pública, sobre temas relacionados, y trabajar con las instituciones nacionales e internacionales que se ocupan"; para compartir el conocimiento y trato con el tema de precaución (particularmente respecto a procesos de producción y productos en torno al cual existen alto nivel de incertidumbre, daño potencial y sensibilidad), unirse a los 
esfuerzos de colaboración de toda la industria (Un Global Compact Red Española del Pacto Mundial, 2015e).

Medioambiente, principio 8: "Las empresas deben fomentar las iniciativas que promuevan una mayor responsabilidad ambiental", menciona entre los pasos para promover la responsabilidad ambiental: definir la visión, las políticas y las estrategias de la empresa para incluir el desarrollo sostenible; para mejorar el desempeño ambiental y extender la responsabilidad en toda la cadena de valor, trabajar con los diseñadores de productos y los proveedores; "Medir, controlar y comunicar los avances en la incorporación de los principios de sostenibilidad en las prácticas de negocio", evaluar resultados y aplicar estrategias para la mejora continua; garantizar el diálogo y la transparencia con las partes interesadas que no esté sesgada” (Un Global Compact Red Española del Pacto Mundial, 2015f).

En medioambiente, principio 9: "Las empresas deben favorecer el desarrollo y la difusión de las tecnologías respetuosas con el medioambiente", se considera que almacenar residuos, su tratamiento y su eliminación, es costoso en términos económicos, ambientales y sociales. Las tecnologías saludables producen menos residuos y desechos, y el uso continuo de tecnologías ineficientes puede representar un aumento en los costes operativos, así como influir retrospectivamente sobre el tipo de control sobre la prevención. Es necesario evitar el impacto ambiental a través del diseño de productos ecológicos y la prevención de la contaminación pues aumenta la eficiencia, la competitividad global y puede producir nuevas oportunidades de negocio. Las tecnologías saludables, al reducir las ineficiencias operativas, producen un nivel inferior de emisiones contaminantes.

Ejemplifica para el nivel de unidad, o lugar de la fábrica básico, se puede lograr la mejora de la tecnología cambiando el proceso o la técnica de 
fabricación, los materiales de entrada, el componente o diseño de los productos, reutilizando materiales. Como algunos enfoques en el nivel estratégico para mejorar la tecnología podrían considerarse suministrar información a las partes interesadas para ilustrar el comportamiento ambiental y los beneficios de utilizar tales tecnologías; reorientar la investigación y el desarrollo hacia un 'diseño para la sostenibilidad'; usar evaluación del ciclo de vida en el desarrollo de productos y nuevas tecnologías; examinar los criterios de inversión y la política de fuentes de proveedores y contratistas para asegurarse de que en sus ofertas se estipulan criterios ambientales mínimos; cooperar con socios de la industria a efectos de asegurar que esté a disposición para otras organizaciones la "mejor tecnología disponible" (Un Global Compact Red Española del Pacto Mundial, 2015g).

Sobre Anticorrupción, principio 10: "Las empresas deben trabajar contra la corrupción en todas sus formas, incluidas extorsión y soborno", el Pacto Mundial de la ONU sugiere a los participantes considerar los siguientes elementos en la aplicación de este principio y la lucha contra la corrupción, en lo interno incluir políticas y programas en sus organizaciones y operaciones comerciales contra la corrupción. En lo externo, sugiere informar sobre el trabajo contra la corrupción dentro del informe anual sobre el progreso y, por medio de la presentación de ejemplos y casos, compartir experiencias y mejores prácticas; en la acción colectiva "unir fuerzas con otras empresas del sector y con otras partes interesadas a intensificar los esfuerzos contra la corrupción” (Un Global Compact Red Española del Pacto Mundial, 2015h).

\section{Resultados}

Para el plan de cuentas se han considerado algunos contenidos de un Plan de Cuentas Ambientales (Arcentales et al., 2007). De lo anterior y de los 
análisis realizados, la taba 3 muestra como resultado el plan considerando los ejemplos para el cumplimiento de los principios del Pacto Global o Mundial de Naciones Unidas. 
Tabla 3. Plan de cuentas para el enfoque socioambiental no financiero

\begin{tabular}{|c|c|c|c|}
\hline Código & Cuenta & Código & Cuenta \\
\hline 1.SA & Activo & 2.SA & Pasivo \\
\hline 1.1.SA & Activo corriente & 2.1.SA & Pasivo corriente cierto y probable \\
\hline 1.1.1 & & 2.1.1.SA & Deudas socioambientales \\
\hline 1.1.2. SA & Inversiones temporarias & 2.1.1.1 & Cantidad de Proveedores Locales \\
\hline \multirow[t]{4}{*}{ 1.1.2.1 } & Inversiones sociales & 2.1.1.2 & Cantidad de Proveedores No Locales \\
\hline & & 2.1.1.3 & Cantidad de Multas y Recamaciones Sociales \\
\hline & (Idem Inversiones permanentes cuando son corrientes) & 2.1.1.4 & Cantidad de Multas y Reclamaciones Ambientales \\
\hline & & 2.1.1.5 & Cantidad de casos de incumplimiento a los convenios colectivos \\
\hline \multirow[t]{4}{*}{ 1.1.2.2 } & Inversiones ambientales & 2.1.1.6 & Previsiones... \\
\hline & & & $\ldots .$. \\
\hline & (Idem Inversiones permanentes cuando son corrientes) & 2.1.2.SA & Otras deudas socioambientales \\
\hline & & 2.1.2.1 & Cantidad de Acreedores Locales \\
\hline 1.1.3. SA & Créditos & 2.1.2.2 & Cantidad de Acreedores No Locales \\
\hline \multirow[t]{4}{*}{ 1.1.3.1 } & Créditos sociales & 2.1.2.3 & Cantidad de Casos por Corrupción \\
\hline & & & $\ldots .$. \\
\hline & (Idem Créditos Sociales permanentes cuando son corrientes) & 2.2.SA & Pasivo no corriente cierto y probable \\
\hline & & & (Idem Pasivo Corriente Cierto y Probable cuando es No corriente) \\
\hline \multirow[t]{4}{*}{1.1 .3 .2} & Créditos ambientales & & \\
\hline & & 3.SA & Patrimonio neto \\
\hline & (Idem CréditosAmbientales permanentes cuando son corrientes) & 3.1.SA & Patrimonio neto interno \\
\hline & & 3.1 & Capital SA del ente \\
\hline \multirow[t]{2}{*}{ 1.1.4. SA } & Otros créditos sociales y ambientales & 3.2 & Aportes SA Capitalizables \\
\hline & & 3.2 & Reservas SA \\
\hline
\end{tabular}

Revista Activos

ISSN: 0124-5805 | e-ISSN: 2500-5278 | DOI: https://doi.org/10.15332/25005278

Vol. 19 N.o 1 | enero-junio de 2021 


\begin{tabular}{|c|c|c|c|}
\hline Código & Cuenta & Código & Cuenta \\
\hline & (IdemOtros CréditosS. y A. permanentes cuando son corrientes) & 3.3 & Resultado Social \\
\hline & & 3.4 & Resultado Ambiental \\
\hline 1.1.5. SA & Bienes de cambio & & $\ldots$ \\
\hline 1.1.5.01 & Materiales no renovables & 3.2.SA & Patrimonio neto comunitario \\
\hline 1.1.5.02 & Materiales renovables & 3.2 .1 & Aportes Sociales Capitalizables para la Counidad \\
\hline 1.1.5.03 & Insumos reciclados & 3.2 .2 & Aportes Ambientales Capitalizables para la Comunidad \\
\hline 1.1.5.04 & Combustibles de fuentes no renovables & & $\ldots$ \\
\hline 1.1.5.05 & Combustibles de fuentes renovables & 4.SA & Resultados \\
\hline 1.1.5.06. & Energía generada & 4.1.SA & Resultados ordinarios \\
\hline 1.1.5.07 & Energía comprada & 4.1.1.SA & Resultados ordinarios operativos \\
\hline 1.1.5.08 & Agua de lluvia recogida & 4.1.1.1.SA & Resultados ordinarios operativos positivos \\
\hline 1.1.5.09 & Agua reciclada & 4.1.1.1.01 & Reciclados o Recuperación de Materiales \\
\hline 1.1.5.10 & Agua adquirida & 4.1.1.1.02 & Reciclado o Recuperación de Insumos \\
\hline 1.1.5.11 & Agua recibida en donación & 4.1.1.1.03 & Generación de Energía \\
\hline \multirow[t]{2}{*}{ 1.1.5.12 } & Agua aportada por los propietarios & 4.1.1.1.04 & Reciclado de Agua \\
\hline & $\ldots$. & 4.1.1.1.05 & Asistencia Sanitaria \\
\hline 1.2. SA & Activo no corriente & 4.1.1.1.06 & Comités formales trabajador-empresa de salud y seguridad \\
\hline 1.2.1. SA & Créditos & 4.1.1.1.07 & Contratación de Altos Ejecutivos \\
\hline 1.2.1.1 & Créditos sociales & 4.1.1.1.08 & Contrataciones de Empleados \\
\hline 1.2.1.1.01 & Puestos de Trabajo Programados & 4.1.1.1.09 & Contratación de Trabajadores \\
\hline 1.2.1.1.02 & Puestos de trabajo bajo Convenios colectivos & 4.1.1.1.10 & Formación y Capacitación Interna \\
\hline 1.2.1.1.03 & Puestos de Empleados bajo Convenios colectivos & 4.1.1.1.11 & Cantidad de Personal con Obra Social \\
\hline 1.2.1.1.04 & Alianzas para evitar el trabajo infantil & 4.1.1.1.12 & Permisos Parentales \\
\hline 1.2.1.1.05 & Alianzas para evitar el trabajo forzoso & 4.1.1.1.13 & Plazos de Preaviso \\
\hline 1.2.1.1.06 & Alianzas para garantizar la igualdad de género & 4.1.1.1.14 & Regeneración natural \\
\hline
\end{tabular}

Revista Activos

ISSN: 0124-5805 | e-ISSN: 2500-5278 | DOI: https://doi.org/10.15332/25005278

Vol. 19 N.o 1 | enero-junio de 2021 


\begin{tabular}{|c|c|c|c|}
\hline Código & Cuenta & Código & Cuenta \\
\hline \multirow[t]{2}{*}{ 1.2.1.1.06 } & Alianzas para garantizar el cumplimiento de convenios colectivos & & ...... \\
\hline & $\ldots$. & 4.1.1.2.SA & Resultados ordinarios operativos negativos \\
\hline \multirow[t]{2}{*}{ 1.2.1.1.07 } & Previsiones por quejas y reclamaciones & 4.1.1.2.01 & Costo consumido en la venta de: \\
\hline & ...... & Ej. SA: & Materiales no renovables \\
\hline 1.2.1.2 & Creditos ambientales & & Materiales renovables \\
\hline 1.2.1.2.01 & Emisiones de GEI Aprobadas & & Materiales reciclados \\
\hline 1.2.1.2.02 & Residuos Aprobados & & Insumos Reciclados \\
\hline 1.2.1.2.03 & Vertidos de Agua Aprobados & & Combustibles de fuentes no renovables \\
\hline \multirow[t]{2}{*}{ 1.2.1.2.04 } & Proyectos Ambientales Aprobados & & Combustibles de fuentes renovables \\
\hline & $\cdots .$. & & Energía generada, Energía adquirida \\
\hline 1.2.2. SA & Otros créditos sociales y ambientales & & $\begin{array}{l}\text { Agua de lluvia recogida y Agua propia reciclada o no, Agua de humedales, } \\
\text { ríos, mares }\end{array}$ \\
\hline 1.2.2.01 & $\begin{array}{l}\text { Estímulos a recibir por Alianzas para el Desarrollo Social de la } \\
\text { Comunidad }\end{array}$ & & Agua adquirida, recibida en donación o aportada por los propietarios \\
\hline \multirow[t]{2}{*}{ 1.2.2.02 } & $\begin{array}{l}\text { Estímulos a recibir por Alianzas para el Desarrollo Ambiental de la } \\
\text { Comunidad }\end{array}$ & & Emisiones directas de GEI (alcance 1 ) \\
\hline & $\ldots .$. & & Vertido de aguas \\
\hline \multirow[t]{4}{*}{ 1.2.3.SA } & Bienes de cambio & & Emisión de Residuos Peligrosos \\
\hline & & & Emisión de Residuos No Peligrosos \\
\hline & (Idem Bienes de Cambio corrientes cuando son no corrientes) & & Multas y Sanciones Ambientales \\
\hline & & & Multas y Sanciones Sociales \\
\hline 1.2.4.SA & Bienes de uso & & \\
\hline 1.2.4.01 & Inmuebles & 4.1.1.2.02 & Baja del Personal \\
\hline 1.2.4.02 & Canteras, Minas, otros & & (Pueden abrise cuentas indiviudales por categoría, grupo etario, \\
\hline 1.2.4.03 & Reservorios de agua & & tipo de vulnerabilidad, nivel de instrucción o capacitación, región, etc.) \\
\hline 1.2.4.04 & Instalaciones para cuidar y preservar la salud y seguridad & 4.1.1.2.03 & Días perdidos por Accidentes (por tipo, lesiones y gravedad) \\
\hline
\end{tabular}

Revista Activos

ISSN: 0124-5805 | e-ISSN: 2500-5278 | DOI: https://doi.org/10.15332/25005278

Vol. 19 N. ${ }^{\circ} 1$ | enero-junio de 2021 


\begin{tabular}{|c|c|c|c|}
\hline Código & Cuenta & Código & Cuenta \\
\hline 1.2.4.05 & Sosfware respetuoso del medio ambiente & 4.1.1.2.04 & $\begin{array}{l}\text { Días perdidos por Enfermedades Profesionales (por tipo, lesiones y } \\
\text { gravedad) }\end{array}$ \\
\hline 1.2.4.06 & Depreciación Acumulada Inmuebles & 4.1.1.2.05 & Amortizaciones/Depreciaciones \\
\hline \multirow[t]{2}{*}{ 1.2.4.07 } & Depreciación Acumulada Minas, Canteras, otros & & ....... \\
\hline & ..... & & \\
\hline 1.2.5.SA & Activos intangibles & 4.1.1.3SA & Gastos de comercialización \\
\hline 1.2.5.1 & Puestos de trabajo & 4.1.1.4.SA & Gastos de administración \\
\hline 1.2.5.1.1 & Puestos de Trabajo Altos Ejecutivos & 4.1.2.1.SA & Resultados ordinarios no operativos positivos \\
\hline $\begin{array}{l}1.2 .5 .1 .1 \\
01\end{array}$ & Puestos de Trabajo Altos Ejecutivos Mujeres & 4.1.2.1.01 & Cantidad de Capacitaciones realizadas al Personal \\
\hline $\begin{array}{l}1.2 .5 .1 .1 \\
02\end{array}$ & Puestos de Trabajo Altos Ejecutivos Hombres & 4.1.2.1.02 & Cantidad del Personal de Seguridad con Obra social \\
\hline 1.2.5.1.2 & Puestos de Trabajo Empleados & 4.1.2.1.03 & Cantidad de Altas de Personal de Seguridad \\
\hline 1.2.5.1.3 & Puestos de Trabajo Trabajadores & 4.1.2.1.04 & Cantidad de viviendas entregadas a los Trabajadores y sus familias \\
\hline 1.2.5.1.4 & Grupo Etario & 4.1.2.1.05 & Cantidad del Personal beneficiado por programas de salud \\
\hline $\begin{array}{l}1.2 .5 .1 .4 \\
01\end{array}$ & Menores de 18 años & 4.1.2.1.06 & Cantidad de personas beneficiadas por programas de seguridad \\
\hline $\begin{array}{l}1.2 .5 .1 .4 \\
02\end{array}$ & De 18 a 35 años & 4.1.2.1.07 & Mejoras tecnologicas \\
\hline $\begin{array}{l}1.2 .5 .1 .4 \\
03\end{array}$ & De más de 35 a 54 años & 4.1.2.1.08 & Mejoras para el desarrollo social de la comunidad \\
\hline $\begin{array}{l}\text { 1.2.5.1.4. } \\
04\end{array}$ & De más de 54 años a 65 años & $\begin{array}{l}4.1 \cdot 2.1 .08 . \\
01\end{array}$ & Cantidad de Capacitaciones realizadas a la Comunidad \\
\hline $\begin{array}{l}1.2 .5 .1 .4 \\
05\end{array}$ & Más de 65 años & $\begin{array}{l}4.1 \cdot 2 \cdot 1 \cdot 08 \\
02\end{array}$ & Cantidad de Prestaciones en salud a la Comunidad \\
\hline 1.2.5.1.5 & Tipo de Vulnerabilidad & 4.1.2.1.09 & Reforestaciones \\
\hline 1.2.5.1.6 & Región & 4.1.2.1.10 & Regeneración natural \\
\hline 1.2.5.1.7 & Nivel de Educación o Intrucción & & ..... \\
\hline
\end{tabular}

Revista Activos

ISSN: 0124-5805 | e-ISSN: 2500-5278 | DOI: https://doi.org/10.15332/25005278

Vol. 19 N. ${ }^{\circ} 1$ | enero-junio de 2021 


\begin{tabular}{|c|c|c|c|}
\hline Código & Cuenta & Código & Cuenta \\
\hline 1.2.5.1.8 & Nacionalidad & 4.1.2.2.SA & Resultados ordinarios no operativos negativos \\
\hline 1.2.5.1.9 & Credo o Religión & 4.1.2.2.01 & Depreciaciones \\
\hline 1.2.5.1.10 & Personal Contratado & 4.1.2.2.02 & Cantidad de Quejas y Reclamaciones Sociales \\
\hline \multirow[t]{2}{*}{ 1.2.5.1.11 } & Operaciones evaluadas sobre riesgos de corrupción & 4.1.2.2.03 & Cantidad de Quejas y Reclamaciones Ambientales \\
\hline & $\cdots \cdot$ & & $\cdots \cdot$ \\
\hline 1.2.5.2 & Desarrollo de tecnologías respetuosas del medio ambiente & 4.2.SA & Resultados extraordinarios \\
\hline 1.2.5.2.1 & Proceso Productivo & 4.2.1.SA & Resultados extraordinarios positivos \\
\hline 1.2.5.2.2 & Producto & 4.2.1.1 & Regeneración natural \\
\hline \multirow[t]{2}{*}{ 1.2.5.2.3 } & Comercialización & 4.2.1.1.01 & Flora \\
\hline & $\ldots .$. & 4.2.1.1.02 & Fauna \\
\hline \multirow[t]{3}{*}{ 1.2.5.3 } & Otros & 4.2.1.1.03 & Tierra \\
\hline & $\ldots$. & 4.2.1.1.03 & Agua \\
\hline & & 4.2.1.1.04 & Aire \\
\hline 1.2.6.SA & Inversiones permanentes & & $\ldots$. \\
\hline 1.2.6.1 & Inversiones sociales & 4.2.2 SA & Resultados extraordinarios negativos \\
\hline 1.2.6.1.1 & Inmuebles como centros deportivos & 4.2.2.01 & Cantidad de personal afectado por pandemias \\
\hline 1.2.6.1.2 & Inmuebles para el cuidado y atención infantil & 4.2.2.02 & Cantidad de hectareas afectadas por plagas \\
\hline 1.2.6.1.3 & Personal Capacitado y Comunicado, por categoría y sexo & 4.2.2.03 & Cantidad de aguada afectada por derrames \\
\hline $\begin{array}{l}\text { 1.2.6.1.3. } \\
01\end{array}$ & Servicios de Miembros del órgano de gobierno & 4.2.2.04 & Cantidad de Inmuebles afectados por fenómenos naturales \\
\hline $\begin{array}{l}\text { 1.2.6.1.3. } \\
02\end{array}$ & Servicios de Empleados & 4.2.2.05 & Amortizaciones/Depreciaciones Extraordinarias \\
\hline $\begin{array}{l}1.2 .6 .1 .3 . \\
03\end{array}$ & Mano de Obra de Trabajadores & & $\ldots$. \\
\hline 1.2.6.1.4 & Obras sociales, por categoría y sexo & & \\
\hline 1.2.6.1.5 & Servicios de Personal de Seguridad, por categoría y sexo & & \\
\hline
\end{tabular}

Revista Activos

ISSN: 0124-5805 | e-ISSN: 2500-5278 | DOI: https://doi.org/10.15332/25005278

Vol. 19 N. ${ }^{\circ} 1$ | enero-junio de 2021 


\begin{tabular}{|c|c|c|c|}
\hline Código & Cuenta & Código & Cuenta \\
\hline 1.2.6.1.6 & Viviendas para los trabajdores y sus familias & & \\
\hline 1.2.6.1.7 & Programas de salud para el personal & & \\
\hline 1.2.6.1.8 & Programas de seguridad para el personal & & \\
\hline 1.2.6.1.9 & $\begin{array}{l}\text { Programas de apoyo a la investigación científicay desarrollo } \\
\text { teconológico }\end{array}$ & & \\
\hline 1.2.6.1.10 & Alianzas para el desarrollo social de la Comunidad & & \\
\hline 1.2.6.1.11 & Capacitación comunitaria & & \\
\hline 1.2.6.1.12 & Programas de ayuda a la comunidad & & \\
\hline \multirow[t]{2}{*}{ 1.2.6.1.13 } & Depreciaciones Acumuladas & & \\
\hline & ..... & & \\
\hline 1.2.6.2 & Inversiones ambientales & & \\
\hline 1.2.6.2.1 & Plantas Forestales y Ornamentales & & \\
\hline 1.2.6.2.2 & Plantas Medicinales & & \\
\hline 1.2.6.2.3 & Plantas Nativas & & \\
\hline 1.2.6.2.4 & Plantas Exoticas & & \\
\hline 1.2.6.2.5 & Bosques y Reservas & & \\
\hline 1.2.6.2.6 & Reservorios de Agua & & \\
\hline 1.2.6.2.7 & Humedales & & \\
\hline 1.2.6.2.8 & Alianzas para el desarrollo ambiental de la Comunidad & & \\
\hline
\end{tabular}

Fuente: elaboración propia, con base en Geba (2019).

Revista Activos

ISSN: 0124-5805 | e-ISSN: 2500-5278 | DOI: https://doi.org/10.15332/25005278

Vol. 19 N.o 1 | enero-junio de 2021 
El plan de cuentas de la tabla 3 incluye aspectos de los principios del Pacto Global. Consiste en un plan de cuentas básico y flexible para una empresa dedicada a la generación de energía, al cual podrían agregarse cuentas pertinentes y adaptarse para otras actividades

Como el objetivo específico es completar un plan de cuentas contable con enfoque socioambiental no financiero, no se ha incluido el rubro caja y bancos para lo social y ambiental, si bien los entes pueden disponer de fondos para, o generado por la dimensión social y ambiental. Si se entiende que la sostenibilidad implica considerar el mediano y largo plazo, se ejemplifican en mayor grado cuentas para el activo no corriente, si bien pueden ser clasificadas como activo corriente en función a su tiempo de permanencia o momento de extinción en el patrimonio del ente. Las cuentas incluidas implican considerar el cambio de enfoque para la sostenibilidad y pueden ser individualizadas con mayor detalle según las necesidades de información de cada ente.

\section{Conclusiones}

Es posible inferir que el intercambio de conocimientos contribuye a comprender la viabilidad del enfoque o perspectiva contable socioambiental según los ODS, considerando lo no financiero como complementario del enfoque económico-financiero tradicional. Respetar especificidades contables para el enfoque socioambiental no financiero contribuiría con la materialidad, la integridad, la exactitud, el equilibrio, la claridad, la comparabilidad y la fiabilidad de la información.

En este sentido, es posible completar un plan de cuentas contable con enfoque socioambiental no financiero para los ODS considerando aspectos desarrollados para los principios del Pacto Global de Naciones Unidas. 
La adaptación al plan de cuentas respeta las especificidades contables, el significado base para activo, pasivo y capital socioambientales y permite reconocer resultados sociales y ambientales desde una óptica no financiera, como causales de aumento o disminución no compensadas al patrimonio social y ambiental, que no provienen de aportes ni retiros de los propietarios del ente.

\section{Referencias}

Accountancy Europe. (2020, julio). Establecimiento de estándares interconectados para informes corporativos Análisis de retroalimentación [reporte de seguimiento]. https://www.accountancyeurope.eu/publications/follow-up-paper-interconnectedstandard-setting-for-corporate-reporting/

Arcentales, D., Barros, X., Bravo Sigüenza, M., Cabrera, E., Cabrera Paredes, O., Campoverde, V., Carpio Carpio, P., Carpio, R., Condo, D., Crespo, M., Chacón, E., Chuisaca, M., Chumbi Pinos, L., Domínguez, J., Faican, A., Flores Rodas, M., Gallegos Calle, F., Garzón, E., ... Vizñay Durán, A. (2007). Plan de Cuentas Ambientales. Recuperado de https://estrucplan.com.ar/plan-de-cuentasambientales/

Ardila, N. (2018, septiembre). El Pacto Global Red Colombia [presentación de diapositivas].

https://www.ccb.org.co/content/download/65629/1314490/file/4.3\%20Pacto\%20 Global\%20-\%20Natalia\%20Ardila.pdf

Consejo Internacional Integrado de Información (2019). Understanding the value of transparency and accountability. https://corporatereportingdialogue.com/wpcontent/uploads/2019/12/Understanding-the-value-of-transparency-andaccountability-paper.pdf

Fernández Lorenzo, L. (2013). El Proceso Contable. En Fernández Lorenzo, L., Chianelli, G., Geba, N., Guarracino, A., Ibarrart, R., Neira, G., Novello, S. y Larramendy, E., Introducción a la teoría y práctica contables (pp. 77-101). Ediciones Haber Ciencias Económicas. 
Geba, N. (2019). El Balance Social para Gestionar Aspectos de Sustentabilidad Empresaria: Aportes del Proceso Contable para Contribuir con la Medición de la Gestión en Dimensiones Socio-ambientales [tesis doctoral, Universidad Nacional de La Plata]. http://sedici.unlp.edu.ar/handle/10915/88938

Geba, N. y Bifaretti, M. (2017). Contabilidad Social y Ambiental: Reflexiones sobre un Capital Socio-ambiental a Mantener como Variable del Modelo [ponencia]. XXXVIII Jornadas Universitarias de Contabilidad. Universidad Nacional del Sur, Departamento de Ciencias de la Administración, Bahía Blanca, República Argentina.

Geba, N., Bifaretti, M. y Rovelli, P. (2020). El capital social y ambiental desde lo contable y la responsabilidad social ante el COVID-19. Enfoques, 7, 3-15.

http://images.engage.espt.thomsonreuters.com/Web/LALEYSAEIMPRESORA/\%7B7e4da953-b6c1-44508120-7c15bdddbbe9\%7D ENFOQUES_7 - Julio_2020.pdf

Geba, N., Bifaretti, M., Rovelli, P. y Pascuzzi Rey, A. (2019). La Carrera de Contador Público en Universidades Privadas de Argentina: La Contabilidad Social y Ambiental Como Asignatura [ponencia]. XL Jornadas Universitarias de Contabilidad. Universidad Maimónides, Ciudad Autónoma de Buenos Aires, República Argentina.

Geba, N., Catani, M., Bifaretti, M. y Sebastián, M. (2016, noviembre). Contabilidad Socioambiental: Una Integración Conceptual para la Sustentabilidad de las Organizaciones Económicas [ponencia]. V Jornadas del Departamento de Contabilidad. Universidad Nacional de La Plata, La Plata, Argentina.

Geba, N., Fernández Lorenzo, L. y Bifaretti, M. (2007). Marco Conceptual para la especialidad contable socioambiental [ponencia]. XXVIII Jornadas Universitarias de Contabilidad. Universidad Nacional de Mar del Plata, Mar del Plata, Argentina. International Federation of Accountants (2020, 23 de junio). IFAC Response to The European Commission's Non-Financial Reporting Directive Review [comunicado de prensa]. https://www.ifac.org/news-events/2020-06/ifac-response-europeancommission-s-non-financial-reporting-directive-review 
International Financial Reporting Standards Foundation (2018). Marco conceptual para la presentación de informes financieros. Parte $A$.

https://incp.org.co/Site/publicaciones/info/archivos/Traduccion-MarcoConceptual-para-Informes-Financieros-Parte-A06042018.pdf

International Financial Reporting Standards Foundation (IFRS). (2019, 2 de julio).

Corporate Reporting Dialogue publishes paper on transparency and accountability. News and Events. https://www.ifrs.org/news-andevents/news/2019/07/corporate-reporting-dialogue-publishes-paper-ontransparency-and-accountability/

International Financial Reporting Standards Foundation. (2007). Norma Internacional de Contabilidad (NIC) 1. Presentación de Estados Financieros. http://www.facpce.org.ar:8080/NORMASWEB/index internacional.php?c=3\&sc $=108$

Naciones Unidas (2015, 25 de septiembre). La Asamblea General adopta la Agenda 2030 para el Desarrollo Sostenible.. Centro de Noticias de la ONU. https://www.un.org/sustainabledevelopment/es/2015/og/la-asamblea-generaladopta-la-agenda-2030-para-el-desarrollo-sostenible/

Pahlen Acuña, R. (2017, 31 de agosto). La Contabilidad Ambiental en el Sector Público [Conferencia]. XII Jornadas Nacionales del Sector Público. Ciudad autónoma de Buenos Aires. https://archivo.consejo.org.ar/congresos/material/12publico/Pahlen.pdf

Programa de las Naciones Unidas para el Desarrollo y Cámara de Industria y Comercio Argentino-Alemana. (2020). Integridad sostenible: una propuesta de comportamiento empresarial responsable que contribuya al ODS 16 en Argentina. https://pactoglobal.org.ar/wp-content/uploads/2020/08/EbookPacto-Global-1FINAL 20200821.pdf

Un Global Compact Red Española del Pacto Mundial. (2015a). Normas Laborales. Principio 3. https://www.pactomundial.org/2015/04/principio-3/

Un Global Compact Red Española del Pacto Mundial. (2015b). Normas Laborales. Principio 4. https://www.pactomundial.org/2015/04/principio-4/

Un Global Compact Red Española del Pacto Mundial. (2015c). Normas Laborales. Principio 5. https://www.pactomundial.org/2015/04/principio-5/ 
Un Global Compact Red Española del Pacto Mundial. (2015d). Normas Laborales. Principio 6. https://www.pactomundial.org/2015/04/principio-6/

Un Global Compact Red Española del Pacto Mundial. (2015e). Medioambiente. Principio 7. https://www.pactomundial.org/2015/04/principio-7/

Un Global Compact Red Española del Pacto Mundial. (2015f). Medioambiente. Principio 8. https://www.pactomundial.org/2015/04/principio-8/

Un Global Compact Red Española del Pacto Mundial. (2015g). Medioambiente. Principio 9. https://www.pactomundial.org/2015/04/principio-9/

Un Global Compact Red Española del Pacto Mundial. (2015h). Anticorrupción. Principio 10. https://www.pactomundial.org/2015/04/principio-10/

Un Global Compact Red Española del Pacto Mundial. (2017a). Derechos Humanos. Principio 1. https://www.pactomundial.org/2017/11/principio-1/

Un Global Compact Red Española del Pacto Mundial. (2017b). Derechos Humanos. Principio 2. https://www.pactomundial.org/2017/11/principio-2/ 